\title{
Curcumin and Other Polyphenolic Compounds in Head and Neck Cancer Chemoprevention
}

\author{
Philipp Baumeister, Maximilian Reiter, and Ulrich Harréus \\ Department of Otorhinolaryngology, Head and Neck Surgery, Ludwig-Maximilians-University Munich, Marchioninistr. 15, \\ 81377 Munich, Germany \\ Correspondence should be addressed to Philipp Baumeister, philipp.baumeister@med.uni-muenchen.de
}

Received 11 January 2012; Revised 17 February 2012; Accepted 5 March 2012

Academic Editor: Luciano Pirola

Copyright $\odot 2012$ Philipp Baumeister et al. This is an open access article distributed under the Creative Commons Attribution License, which permits unrestricted use, distribution, and reproduction in any medium, provided the original work is properly cited.

\begin{abstract}
Despite clear results of observational studies linking a diet rich in fruits and vegetables to a decreased cancer risk, large interventional trials evaluating the impact of dietary micronutrient supplementation, mostly vitamins, could not show any beneficial effects. Today it has become clear that a single micronutrient, given in supernutritional doses, cannot match cancer preventive effects of whole fruits and vegetables. In this regard polyphenols came into focus, not only because of their antioxidant potential but also because of their ability to interact with molecular targets within the cells. Because polyphenols occur in many foods and beverages in high concentration and evidence for their anticancer activity is best for tissues they can come into direct contact with, field cancerization predestines upper aerodigestive tract epithelium for cancer chemoprevention by polyphenols. In this paper, we summarize cancer chemopreventive attempts with emphasis on head and neck carcinogenesis and discuss some methodological issues. We present data regarding antimutagenic effects of curcumin and epigallocatechin-3-gallate in human oropharyngeal mucosa cultures exposed to cigarette smoke condensate.
\end{abstract}

\section{Introduction}

About two-thirds of head and neck squamous cell carcinomas (HNSCC) can be attributed to heavy tobacco and alcohol consumption. These cancers develop predominantly in men in their sixties [1]. Tobacco carcinogens exert their harmful effects in large fields of upper aerodigestive tract mucosa during decades of smoking. Thus, mucosa cells stepwise accumulate genetic alterations that drive cells towards malignancy. Slaughter's concept of field cancerization best explains head and neck carcinogenesis, that HNSCC patients often suffer from syn- or metachronous cancers and have a high risk for local recurrences or second primary tumors. According to this concept, head and neck squamous cell carcinomas arise from multifocal precancerous lesions within large areas/fields of condemned mucosa in the oral cavity, pharynx, and larynx [2]. It seems obvious that in the same manner chemical carcinogens harm the epithelium, preventive agents might protect it. Cancer chemoprevention was initially supposed by Sporn in 1976. The term describes the use of specific natural, biologic, or synthetic agents to reverse, suppress, or prevent the development of epithelial cancer. Sporn reasoned that it usually takes several years until the final, invasive stage of epithelial malignancies is reached. Therefore, the progression of precancerous lesions could be stabilized, arrested, or reversed [3]. 10 years later, Hong and colleagues showed in a landmark study that following treatment with 13-cis-retinoic acid, the size of oral leukoplakia, a known precancerous lesion of the oral cavity, decreased in $67 \%$ of patients given the drug, compared with $10 \%$ in the placebo arm. Moreover, the vitamin A derivate significantly reversed dysplasia [4].

\section{Chemoprevention of (Head and Neck) Cancer}

Cancer is a largely preventable disease. Thirty years ago, Doll and Peto estimated that about 35\% of all cancer deaths in the United States of America might be attributable to dietary factors [5]. During the 1980s and 1990s, researchers intensively investigated the role of dietary factors in upper aerodigestive 
tract cancers. Multiple case-control studies showed an inverse correlation between fruit and vegetable intake and the risk for cancer of the oral cavity and pharynx [6-9]. Peto et al. also hypothesized in 1981 that $\beta$-carotene might reduce the incidence of all cancers, especially lung cancer [10]. In 1994 , evidence had accumulated that $\beta$-carotene and the synthetic retinoid isotretinoin have chemopreventive effects in multistep field carcinogenesis of the upper aerodigestive tract and lung [11].

In 1988 a large interventional trial was launched including more than 18000 men and women at high risk for lung cancer. The Beta-Carotene and Retinol Efficacy Trial (CARET) tested the combination of $30 \mathrm{mg} \beta$-carotene and $25000 \mathrm{IU}$ vitamin A/per day against placebo. Surprisingly, the trial needed to be stopped 21 month, before completion because of clear evidence of no benefit and substantial evidence of potential harmful effects. There were $28 \%$ more lung cancers and $17 \%$ more deaths in the active intervention group [12].

Another large-scale interventional trial evaluated the effects of $\alpha$-tocopherol (vitamin E) and $\beta$-carotene on cancer incidences. The ATBC trial included 29133 male cigarette smokers randomly assigned to receive $\alpha$-tocopherol, $\beta$-carotene, a combination of both or placebo. Median followup was 6.1 years. In the $\beta$-carotene group, no decrease in cancer incidences was seen, but rather an increase at several sites, including the lung and stomach. The vitamin E group had fewer incidences in prostate and colorectal, but more stomach cancers [13]. Subgroup analyses for the upper aerodigestive tract showed no effect of either agent on overall incidence of oral, pharyngeal, and laryngeal carcinomas or mortality from these tumors. The results suggested a minor protective effect of $\beta$-carotene on incidences of early stage larynx cancers [13]. The EUROSCAN study looked for positive effects of retinyl palmitate (vitamin A) and $\mathrm{N}$ acetylcysteine on overall survival, event-free survival and incidence of second primary tumors of head and neck and lung cancer patients. In 2592 patients, 60\% suffering from head and neck, $40 \%$ from lung cancer, no benefit for the intervention group could be shown [14].

After decades of intensive research the scientific community ended up with little evidence for beneficial effects, but clear evidence for harmful effects of micronutrients. In 1999, Byers discussed the reasons why there is this large gap between the findings of observational studies and interventional trials. He found several factors that need to be considered. First, observational studies generally reveal weaker relationships between cancer and nutrients taken as dietary supplementation, most probably because of variability in reporting of doses taken and patterns of use. Second, the randomized controlled trials completed followed the investigational paradigm of pharmacology by testing micronutrients in supernutritional doses. The basic assumption that high doses of a single nutrient would reproduce the effects of the complex mixture of nutrients found in whole foods might be wrong. But whole foods or whole-diet interventions, he emphasized, cannot easily be incorporated in those trials, certainly not in a blinded way. Third, for reasons of feasibility, such trials evaluate only individuals at high risk for cancers within a short period of time. Since randomized controlled trials are designed to answer narrowly defined questions, it may be unwise to study only those at high risk [15].

\section{Rationales for Head and Neck Cancer Chemoprevention}

Chemoprevention of head and neck cancer is exceptionally interesting because many cancers develop from premalignant lesions, often readily accessible for clinical and histopathological examination. Moreover, as a result of field cancerization, HNSCC patients are at high risk for local recurrences or second primary tumors, an excellent endpoint for clinical trials. Due to life style factors and health behaviors, HNSCC patients often exhibit poor dietary conditions before treatment [16]. Besides smoking, the strongest predictor of survival, low fruit intake, is negatively associated with survival [17].

Upper aerodigestive tract mucosa is the primary target of tobacco smoke, a complex mixture of about 7000 chemical compounds including a high concentration of oxidants [18]. One cigarette puff contains $10^{14}-10^{16}$ radicals, mainly reactive oxygen species (ROS) [19]. Thus, cellular antioxidant defense capacity is easily exceeded leading to oxidative damage of macromolecules such as proteins, lipids and DNA. While the former can be replaced during physiological turnover, genetic material needs to be repaired [20]. During carcinogenesis, chemicals and oxidative stress lead to DNA alterations and evoke an inflammatory response that causes even more oxidative stress [21]. In addition, besides their intrinsic DNA-damaging properties, elimination of tobacco carcinogens, causes oxidative stress, not only during metabolic activation but also by being conjugated with and thereby depleting glutathione, a major nonenzymic antioxidant of the cell [22]. One of the most frequent ROS-induced DNA alterations is 8-oxo-guanine, which leads to frequent misincorporations of adenine in the opposite DNA strand. The resulting $\mathrm{G}: \mathrm{C}$ to $\mathrm{A}: \mathrm{T}$ transversion represents the most predominant somatic mutations in a wide range of epithelial malignancies [23]. Hence, tobacco smoke derived oxidative stress is a major source of DNA damage and mutagenicity. Therefore, orally administered high doses of potent antioxidant micronutrients such as $\beta$-carotene, $\alpha$-tocopherol, or ascorbic acid in order to compensate oxidative stress seemed to be the most promising strategy for upper aerodigestive tract cancer chemoprevention-but, as stated earlier, failed. On the molecular level, a possible explanation for this failure is that high doses of antioxidants may have prooxidant effects, as it was supposed by Halliwell for vitamin E [24]. We showed that vitamin C loses its DNA protective effects in oxidative stressed cells at high concentrations and increases DNA damage caused by hydrogen peroxide [25].

\section{Polyphenols in Cancer Prevention}

In the late 1990s epidemiologists became aware of a phenomenon called the French Paradox. Despite high levels of risk factors such as smoking, hypertension, diabetes, and dietary fat, France has a comparably low mortality rate from 
cardiovascular diseases. This observation was at least partly explained by high consumption of wine. Pronounced in the southwest of France, high levels of red wine intake also seemed to decrease mortality rates from lung cancer [26]. The validity of this conclusion was later questioned because the protective effect was not seen in other countries with similar or even higher wine consumption than France, but much attention was drawn to the potential health benefits of grapes and wine. Phenolic acids and polyphenols, in total $1.2 \mathrm{~g}$ per litre red wine, came into focus [27].

\section{Resveratrol and Tannins}

Resveratrol is a natural phenol produced by several plants. The phytoalexin was detected in high concentrations in the skin of red grapes and is believed to protect them from environmental stress and infections. In red wines, its concentration is approximately $2.0-40.0 \mu \mathrm{M}$ [28]. Regarding HNSCC, only experimental data is available so far. El Attar and Virji reported in 1999 that resveratrol was effective inhibiting growth and proliferation of an oral cancer cell line at concentrations found in red wines [29]. Other studies proved its effectiveness in preventing intestinal and colon cancer in rodents. Due to its poor systemic bioavailability, human interventional trials are difficult to conduct, but at the moment one study is ongoing regarding possible effects on colonic mucosa from colon cancer patients $[30,31]$. The strongest evidence of anticancer action of resveratrol exists for tumors derived from tissues with which resveratrol can come into direct contact [32], thus making it a prime candidate for HNSCC chemoprevention.

Tannins are also found in large quantities in red wine and were shown to act as both anti-initiating and antipromoting agents in experimental animals [33]. In mouse epidermal JB6 cells, tannins blocked epidermal growth factor-induced tumor promotion [34].

\section{Quercetin}

Quercetin is another polyphenol found in fruits, nuts, herbs, and vegetables, as well as in wine. It is normally present in its glycosylated form, but digestive cleavage of the glycosides catalyzed by $\beta$-glycosidases already begins in the oral cavity [35]. It is a potent scavenger of (oxygen) radicals and chelator of metal ions involved in ROS production [36], and it induced the expression of human 8-oxo-guanine DNA glycosylase, an enzyme involved in the repair of oxidative damaged DNA, in Caco-2 cancer cells [37]. But, quercetin is a two-edged sword, because in concentration greater than $40 \mu \mathrm{M}$, it increased oxidative stress in Chinese hamster ovary cells [38]. Chemopreventive effects in mice were shown by De and colleagues. Orally administered quercetin restricted the progression of cervical dysplastic lesions [39]. In humans, it has a comparable poor systemic bioavailability as resveratrol [30].

\section{Epigallocatechin-3-Gallate (EGCG)}

Tea is one of the most widely consumed beverages in the world. Flavanols, commonly referred to as tea catechins, notably epicatechin, epicatechin-3-gallate, epigallocatechin and epigallocatechin-3-gallate (EGCG), represent about 3$10 \%$ of the dry weight of black tea and $30-42 \%$ of green tea, respectively. Orally administered, bioavailability of EGCG was found to be about $16 \%$ in rats. There seems to be no considerable presystemic hepatic metabolism [40]. Even though antioxidant properties of tea catechins are well established in vitro [41], the rationale for chemoprevention trials is largely based on its molecular mechanisms. Dong and colleagues identified vimentin, insulin-like growth factor 1 receptor and Ras-GTPase-activating protein SH3 domain-binding protein 1 as high affinity binding targets for EGCG, all of which were shown to be involved in EGCG-mediated growth inhibition in various cancer cell lines [42-44]. Of particular interest regarding head and neck carcinogenesis, EGCG was demonstrated to have inhibitory effects on epidermal growth factor receptor (EGFR) signalling pathways as detected in esophageal cancer, epidermoid carcinomas and colon cancer cell lines [45-48]. Further targets of EGCG and molecular mechanisms of action are reviewed by Yang and colleagues [49]. Despite these laboratory findings, a meta-analysis by the Cochrane collaboration of 51 studies including more than 1.6 million participants could not find sufficient evidence for cancer chemopreventive effects of drinking (green) tea [50].

\section{Curcumin}

Curcumin, the yellow pigment in tumeric, is widely used as a spice and has various properties such as antioxidant, immunomodulation, antiangiogenesis, and induction of apoptosis [32]. It was shown to effectively inhibit growth of normal human oral epithelial cells and cell lines derived from both oral precancerous lesions and squamous cell carcinomas [51]. Moreover, curcumin decreased incidence and volume of chemically induced oral cancers in rats [52]. In a prospective trial of patients at high risk for the development of epithelial cancer in several organs, oral intake of curcumin up to $8 \mathrm{~g} /$ day had no toxic effects in humans and led to histologic improvement of oral leukoplakia in 2 of 7 patients during 3 months of administration [53]. In 25 patients with oral leukoplakia treated with $900 \mathrm{mg}$ curcumin, $80 \mathrm{mg}$ desmethoxycurcumin and $20 \mathrm{mg}$ bisdesmethoxycurcumin per day, serum and salivary vitamin $C$ and E levels were found to increase, while markers for oxidative stress in serum and saliva decreased [54]. In head and neck cancer cell lines, curcumin was shown to target various molecular pathways including caspase-3 dependent signalling, Notch-1 and NF$\kappa \mathrm{B}$ pathways. This resulted in the induction of apoptosis and general growth inhibition of the cell lines [55-59].

\section{Methodological Considerations}

Some theoretical points regarding chemopreventive research need to be considered. Growth inhibitory or proapoptotic effects of polyphenols in cancer cell lines do not indicate chemopreventive, but rather chemotherapeutic effects. The use of cancer derived cell lines to evaluate possible effects of polyphenols on various cellular signalling pathways and protein expression should at least be questioned. 
In this respect, epidermal growth factor receptor (EGFR) biology is a good example. About $80-90 \%$ of HNSCC show high expression of EGFR. Since high EGFR levels have been detected in premalignant lesion and increasing levels were found during malignant progression, the receptor is a widely accepted biomarker for head and neck carcinogenesis [60]. This made the receptor an interesting target for chemoprevention on the basis of anticipated inhibition of malignant transformation.

We investigated the role of EGFR biology in the context of chemical carcinogenesis caused by benzo(a)pyrene $(B(a) p)$ and found that EGFR stimulation significantly reduces $\mathrm{B}(\mathrm{a}) \mathrm{p}$-induced DNA fragmentation in premalignant oropharyngeal mucosa cells exhibiting high EGFR expression. This effect was totally abrogated when the receptor was blocked in advance $[61,62]$. Thus, in premalignant mucosa of head and neck cancer patients, EGFR stimulation protects the cell from $\mathrm{B}(\mathrm{a}) \mathrm{p}$, most probably as a result of EGFR downstream activation of a multidrug resistance efflux pump [63] capable of extruding the carcinogen from the cell $[64,65]$. Furthermore, evidence is mounting that EGFR levels correlate with tobacco consumption and might, hence, represent a physiological response to its carcinogenic impact.

On the other hand, in HNSCC EGFR serves as an independent prognostic marker associated with resistance to nonsurgical therapies and poor survival [66]. Particularly, increased EGFR expression was linked to poor response to platinum-based chemotherapy. Cetuximab, a monoclonal EGFR antibody, was shown to be effective in cisplatinresistant cancers [67]. The very same efflux pumps involved in $\mathrm{B}(\mathrm{a}) \mathrm{p}$-extrusion are implicated in the resistance to chemotherapeutic drugs like cisplatin [68]. Named according to their function in antimicrobial and anticancer chemotherapy, it has now become clear that these pumps rather confer a general defense against xenobiotics and are highly conserved in all living organisms [69].

Therefore, EGFR inhibition, for example, by EGCG, certainly leads to growth inhibition in cell line experiments and might render cancer cells more sensitive to cytotoxic drugs. But it might also diminish cellular defense against carcinogens in premalignant mucosa. This illustrates that the modification of cellular signalling pathways or protein expression might have a different impact in non-/premalignant cells and cancer cells, respectively.

For the above reasons the most appropriate in vitro model for cancer chemopreventive trials has not yet been identified. Animal models show their strength when potential chemopreventive agents suppress or even reverse artificially induced malignant transformation of epithelial cell despite the fact that it is obviously not the primary organism of interest. In our laboratory we use tissue cultures of fresh biopsied human upper aerodigestive tract mucosa since many years. First described by Steinsvåg and colleagues for nasopharyngeal adenoid tissue [70], we applied the model for nasal and oropharyngeal mucosa. Samples harvested during surgery on lower nasal turbinates, palatine tonsils and soft palate are kept in culture for several weeks until three-dimensional tissue cubes consisting of a connective tissued core and completely coated with ciliated or squamous epithelium have emerged. For the evaluation of carcinogenic impact of xenobiotics on upper aerodigestive tract mucosa, mostly isolated mucosa cells are applied. Compared to cells kept in their surrounding tissue, however, single cells may have only a limited metabolic competence, not only for xenobiotics but also for endogenous-derived compounds. Moreover, single cells are not best suited for repetitive tests because of considerable loss of cellular material. As mentioned above, head and neck carcinogens strike their targets in a chronic manner. Nasal or oropharyngeal mucosa cultures can easily be exposed to multiple incubations with xenobiotics without considerable cellular damage in terms of viability and can be transferred by careful aspiration between containers without cellular loss. Moreover, in these tissue cultures, primary mucosa cells survive for several weeks. Therefore, our tissue culture model represents the primary target tissue of inhaled or ingested xenobiotics and carcinogens. It allows repetitive incubations not only with chemical carcinogens but also with chemopreventive compounds [71].

\section{DNA Protection by Polyphenols in Human Mucosa Tissue Cultures}

A carcinogen is defined as a physical, chemical, or biological agent or a combination of agents that produces cancer in an organism. The International Agency for Research on Cancer (IARC) recently classified tobacco smoke as carcinogenic to humans (group 1) [72]. This classification also applies for benzo(a)pyrene $(\mathrm{B}(\mathrm{a}) \mathrm{p})$, which was recently upgraded from group 2B (possibly carcinogenic to humans) to group 1 [73]. The majority of known chemical carcinogens are also mutagens, hence, agents that produce a genetic event resulting in a heritable genetic change [74]. B(a)p and its activated metabolite benzo(a)pyrene diol epoxide (BPDE) are wellknown mutagens [75]. BPDE binds to DNA in vitro and in vivo and forms adducts, particularly within the p53 tumor suppressor gene [76]. As described above, oxidative stress also leads to DNA alterations. Although hydrogen peroxide, widely used to induce oxidative stress, causes DNA damage in vivo and in vivo [77], IARC found only inadequate evidence for its carcinogenicity in humans and limited evidence for carcinogenicity in experimental animals, therefore classifying it as group 3 (not classifiable as to its carcinogenicity to humans) [78].

Using nasal and oropharyngeal mucosa tissue cultures, we previously evaluated the ability of epigallocatechin-3gallate (EGCG), tannins, and quercetin to prevent DNA damage. Cultures were incubated with the polyphenols before DNA was damaged by cigarette smoke condensate (CSC), BPDE, or hydrogen peroxide. Genotoxicity was quantified by the comet assay. To test EGCG, oropharyngeal mucosa cultures were incubated with EGCG before DNA fragmentation was introduced by BPDE, which was previously shown to induce dose-dependent DNA migration detectable by the comet assay in human cells [79]. The treatment with EGCG significantly decreased BPDE-induced DNA damage in a dose-dependent manner. In a further series of tests, tissue cultures were incubated with EGCG on only 1 or on 4 days for 30 minutes. DNA damage was induced 
by CSC during an 18-hour-incubation period. Here, DNA damage was decreased by $28 \%$ after 1 and by $47 \%$ after 4 incubations [80]. Similar results were seen when cultures were exposed to tannins during 30 minutes on 3 days. DNA fragmentation caused by BPDE went down by more than $40 \%$ [81].

In cultures produced of nasal mucosa quercetin significantly prevented DNA damage caused by hydrogen peroxide, again in a dose-dependent manner [82].

For the study presented here we used oropharyngeal mucosa. Cultures were incubated with curcumin, EGCG or both. DNA damage was introduced by cigarette smoke condensate and quantified using the comet assay.

\section{Materials and Methods}

11.1. Tissue Material. The trial was approved by the ethics committee of Ludwig-Maximilians-University, Munich, Germany. After given informed consent, mucosa samples were harvested during surgical therapy of chronic tonsillitis and/or obstructive sleep apnoea syndrome. Tissue samples were obtained during tonsillectomy and uvulopalatopharyngoplasty. After excision, samples were covered with $0.9 \%$ $\mathrm{NaCl}$ solution.

11.2. Cell Culture Procedure. After immediate transport to the laboratory, specimens were dissected into mucosal cubes of $1 \mathrm{~mm}^{3}$ excluding deeper layers. Specimens were then transferred into a tube containing $5 \mathrm{~mL}$ Phosphate Buffered Salina (PBS, Gibco invitrogen, Eggenstein, Germany), washed three times in PBS, and placed in 24-well plates, one fragment in each well. Bottoms of wells were coated with $30 \mathrm{~mL}$ 0.75\% Agar Noble (DIFCO, Detroit, USA) dissolved in $30 \mathrm{~mL}$ Dulbecco's modified eagle medium (DMEM), $6 \mathrm{~mL}$ $10 \%$ fetal calf serum (Gibco), $75 \mu \mathrm{L}$ nonessential amino acids (Gibco), $240 \mu \mathrm{L}$ penicillin-streptomycin (Sigma Aldrich, Steinheim, Germany), and $120 \mu \mathrm{L}$ amphotericin B (Gibco), thus preventing adhesion to the surface. Cultures were now covered with $250 \mu \mathrm{L}$ Bronchial Epithelial Cell Growth Medium (BEGM, supplemented with Bovine Pituitary Extract, insulin, hydrocortisone, epinephrine, triodothyronine, transferring, and retinoic acid; Promocell; Heidelberg, Germany) per well. After about 21 days incubated at $37^{\circ} \mathrm{C}$, $5 \% \mathrm{CO}_{2}$, and $100 \%$ relative humidity, mucosa cultures were completely coated with epithelium. Growth medium $(250 \mu \mathrm{L}$ BEGM) was renewed every second day; every seventh day multiwell plates were changed. When transferred, cultures were mildly aspirated with a pipette, thus preventing damage to the cells as far as possible.

11.3. Incubations. In a first experimental arm, 20 mucosa cultures were incubated with $1 \mu \mathrm{mol} / \mathrm{L}$ curcumin for $60 \mathrm{~min}$ utes on 1 or 4 consecutive days. The concentration was determined by dose-response experiments (data not shown). BEGM was replaced twice after all incubations. Directly after the last incubation, cultures were exposed to cigarette smoke condensate (CSC, $0.7 \mathrm{mg} / \mathrm{mL}$; produced of Marlboro Flavor Mix; Analytisch-Biologisches Forschungslabor, Munich, Germany) for 18 hours. All reagents were solved in dimethyl sulfoxide (DMSO, Merck, Darmstadt, Germany), which was used as negative control. In a second experimental arm, 20 cultures were exposed to $1 \mu \mathrm{mol} / \mathrm{L}$ curcumin for 1 hour and $0.5 \mu \mathrm{mol} / \mathrm{L}$ EGCG for 30 minutes to evaluate possible synergistic effects. Again, CSC was incubated for 18 hours.

11.4. Comet Assay. To quantify resulting DNA damage the alkaline version of the single cell microgelelectrophoresis (comet assay) was applied. The assay is capable of detecting DNA double- and single-strand breaks as well as alkaline labile sites and transient repair sites [83].

Mucosa cultures underwent enzymic digestions for 1 hour after being covered with a solution of $50 \mathrm{mg}$ protease (Biochrom, Heidelberg, Germany), $10 \mathrm{mg}$ hyaluronidase (Roche, Mannheim, Germany), and $10 \mathrm{mg}$ collagenase P (Roche) dissolved in $10 \mathrm{~mL}$ BEGM. Thereafter, connective tissue and extracellular matrix components were carefully removed. Histolytic enzymes were neutralized with fetal calf serum (Gibco), and the cell suspension was washed twice in cold PBS (Gibco). Cell viability was monitored by the trypan blue dye exclusion test.

Comet assay was carried out according to the standard protocol [84]. DNA migration was measured using the image analysis software Komet 3.1 (Kinetic Imaging, Liverpool, UK) and quantified by the percentage of DNA in the tail (\% tail DNA) [85]. 80 cell nuclei per slide were randomly selected without knowledge of pretreatment.

11.5. Statistical Analysis. Significant differences in DNA damage were calculated using the Wilcoxon Signed-Rank test by the SPSS 18.0 software (SPSS GmbH, München, Germany). Alpha level was set at 0.05 prior statistical analyses and adjusted according to the Bonferoni correction because of multiple testing. Significant $\alpha$-levels are indicated in figures.

\section{Results}

Cell viability verified using the trypan blue staining test was constantly $>90 \%$, thus excluding major cytotoxic effects of the substances tested.

In the first experimental arm, DMSO used as the solvent for all other chemicals, as well as curcumin added on 1 or 4 days, did not cause considerable DNA damage. CSC did induce DNA fragmentation mean \% tail DNA was 19.1. Previous exposure to curcumin within 60 minutes led to a reduction of DNA damage by $31.4 \%$ to $13.1 \%$ tail DNA. When cultures were incubated with curcumin on 4 days, DNA fragmentation was reduced by $47 \%$ to $10.1 \%$ tail DNA, which reflects a significant further decrease of CSC-induced genotoxicity (see Figure 1).

These results were confirmed in the second experimental arm. Again, the solvent, curcumin, and EGCG did not cause DNA fragmentation (data not shown). Curcumin decreased CSC-induced DNA fragmentation by $25.8 \%$ ( 1 day) and $47.1 \%$ (4 days), respectively. EGCG added on 1 or 4 days did also significantly reduce CSC-caused genotoxicity. \% tail DNA went down from 24.0 to $18.8(21.7 \%)$ and to 13.8 , respectively (42.5\%; see Figure 2). 


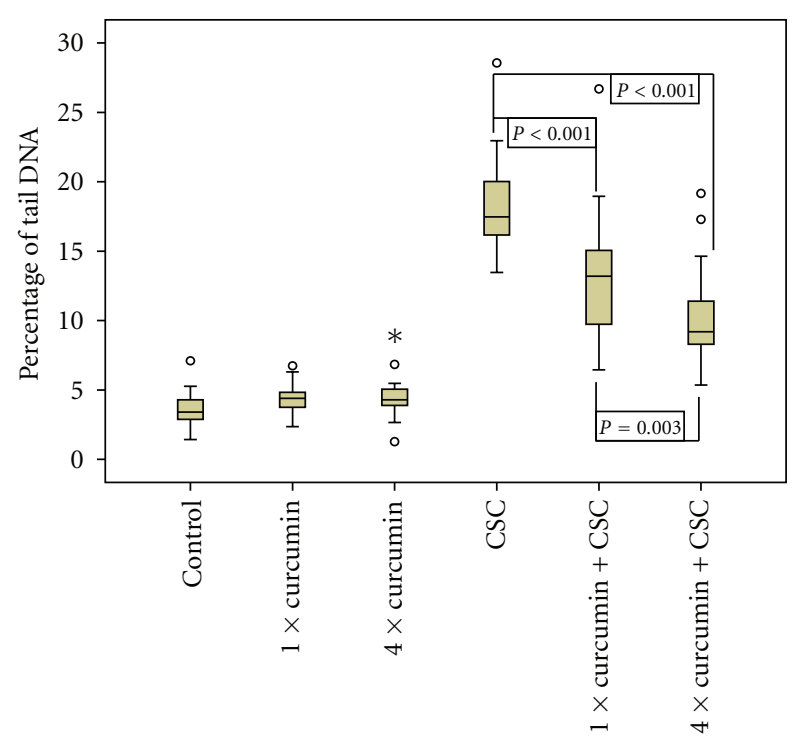

Figure 1: DNA damage (\% tail DNA) caused by cigarette smoke condensate (CSC), after previous incubation with Curcumin on 1 day or on 4 days $\left(n=20\right.$; o $=$ outlier value, ${ }^{*}=$ extreme value; $\alpha$ level $=0.02$ ).

Both polyphenols added together did not show synergistic effects. When incubated in 1 day, the combination of both substances did not further increase the effect of both curcumin and EGCG, but still significantly reduced genotoxicity of CSC. When added on 4 days, the combination of both substances did no longer significantly reduce CSC-induced genotoxicity after $\alpha$-level was set to 0.006 according to the Bonferoni correction (see Figure 2).

\section{Conclusion}

In our study, mucosa cultures were incubated with curcumin, epigallocatechin-3-gallate (EGCG), or both on 1 day or on 4 consecutive days. After all incubations, the growth medium was replaced twice. Finally cultures were exposed to cigarette smoke condensate (CSC) for 18 hours. The result was a highly significant reduction of CSC-caused genotoxicity as evaluated by the comet assay in all experiments except for the combination of curcumin and EGCG incubated on 4 days. No additive effects were detected when curcumin and EGCG were added simultaneously. Compared to the other polyphenols tested in our laboratory, curcumin was most effective preventing tobacco-related DNA damage. All compounds reduced genotoxic effects of $\mathrm{B}(\mathrm{a}) \mathrm{p}$ or CSC in a dose-dependent manner [80, 81].

Bearing in mind that tobacco smoke is carcinogenic to humans and responsible for the vast majority of head and neck cancers, our results demonstrate promising chemopreventive potentials of curcumin and EGCG. Since we used oropharyngeal mucosa cultures as a primary human target tissue of tobacco smoke, the experimental setting represents a good compromise between in vivo studies in animals and human cell line experiments. Taken together, this study and previous results of our laboratory indicate

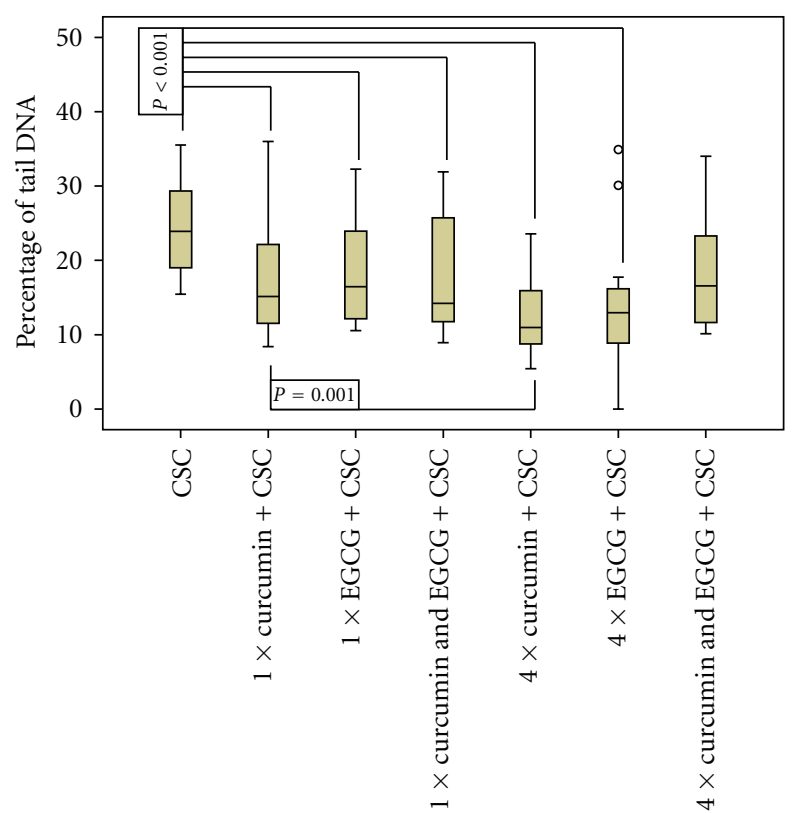

FIGURE 2: DNA damage ( $\%$ tail DNA) caused by cigarette smoke condensate (CSC), after previous incubation with curcumin, epigallocatechin-3-gallate (EGCG), or both, on 1 day or on 4 days $(n=20 ;$ o $=$ outlier value; $\alpha$-level $=0.006)$.

that dietary polyphenols are capable of preventing tobaccorelated genotoxicity in upper aerodigestive tract mucosa. A diet high in fruits and vegetables remains the major source of polyphenolic compounds and was repeatedly shown to lower the risk for HNSCC. Unfortunately, many heavy smokers do not exploit this source due to life-style habits.

Despite the disappointing findings of large interventional trials evaluating the impact of dietary micronutrient supplementation, mostly vitamins, on cancer incidences, the clear results of observational studies remain valid. Even if it could not be shown that one single agent or a combination of two can be as effective as whole fruits and vegetable, it is still in this diet and therefore a matter of time, until the network and interactions of micronutrients involved are better understood. Vitamin E, for example, is a complex mixture of 16 chemical compounds including 4 tocopherols. In the western diet, the most prevalent vitamin $\mathrm{E}$ compound is $\gamma$-tocopherol and high serum levels were shown to be inversely associated with cardiovascular diseases. Gamma Tocopherol is poorly retained after intestinal absorbtion, and $\alpha$-tocopherol, widely used for dietary supplementation, reduces further serum concentration of $\gamma$-tocopherol [8688]. Moreover, several vitamins in high supernutritional doses might be more harmful than protective. The old sentence of Paracelsus "dosis facit venenum" seems to be particularly true in this regard.

It becomes clear that micronutrient supplementation cannot mimic a diet rich in whole fruits and vegetables. Polyphenols recently came into focus, not only because of their powerful antioxidant effects but also because of their ability to interact with cellular signalling pathways. In this regard, as stated above, we need to carefully distinguish 
chemopreventive and rather chemotherapeutic effects. Nevertheless, polyphenols showed promising anticancer and antimutagenic action. The fact that several phenolic compounds are present in beverages in high concentrations makes them good candidates for head and neck cancer chemoprevention. Since evidence for anticancer effects is best for tissues they can come into direct contact with, upper aerodigestive mucosa, target of field cancerization, seems to be one of the best-suited tissues.

\section{Abbreviations}

HNSCC: Head and neck squamous cell carcinoma

ROS: $\quad$ Reactive oxygen species

EGCG: Epigallocatechin-3-gallate

EGFR: Epidermal growth factor receptor

B(a)p: Benzo(a)pyrene

BPDE: Benzo(a)pyrene diol epoxide

CSC: Cigarette smoke condensate.

\section{References}

[1] P. Vineis, M. Alavanja, P. Buffler et al., "Tobacco and cancer: recent epidemiological evidence," Journal of the National Cancer Institute, vol. 96, no. 2, pp. 99-106, 2004.

[2] D. P. Slaughter, H. W. Southwick, and W. Smejkal, "Field cancerization in oral stratified squamous epithelium: clinical implications of multicentric origin," Cancer, vol. 6, no. 5, pp. 963-968, 1953.

[3] M. B. Sporn, "Approaches to prevention of epithelial cancer during the preneoplastic period," Cancer Research, vol. 36, no. 7, pp. 2699-2702, 1976.

[4] W. K. Hong, J. Endicott, and M. Itri, "13-cis-retinoic acid in the treatment of oral leukoplakia," New England Journal of Medicine, vol. 315, no. 24, pp. 1501-1505, 1986.

[5] R. Doll and R. Peto, "The causes of cancer: quantitative estimates of avoidable risks of cancer in the United States today," Journal of the National Cancer Institute, vol. 66, no. 6, pp. 1191-1308, 1981.

[6] D. M. Winn, R. G. Ziegler, and L. W. Pickle, "Diet in the etiology of oral and pharyngeal cancer among women from the southern United States," Cancer Research, vol. 44, no. 3, pp. 1216-1222, 1984.

[7] E. L. Franco, L. P. Kowalski, B. V. Oliveira et al., "Risk factors for oral cancer in Brazil: a case-control study," International Journal of Cancer, vol. 43, no. 6, pp. 992-1000, 1989.

[8] T. Takezaki, K. Hirose, M. Inoue et al., "Tobacco, alcohol and dietary factors associated with the risk of oral cancer among Japanese," Japanese Journal of Cancer Research, vol. 87, no. 6, pp. 555-562, 1996.

[9] F. Levi, C. Pasche, C. la Vecchia et al., "Food groups and risk of oral and pharyngeal cancer," International Journal of Cancer, vol. 77, no. 5, pp. 705-709, 1998.

[10] R. Peto, R. Doll, J. D. Buckley, and M. B. Sporn, "Can dietary beta-carotene materially reduce human cancer rates?" Nature, vol. 290, no. 5803, pp. 201-213, 1981.

[11] S. M. Lippman, S. E. Benner, and W. K. Hong, "Retinoid chemoprevention studies in upper aerodigestive tract and lung carcinogenesis," Cancer Research, vol. 54, no. 7, 1994.

[12] G. S. Omenn, G. E. Goodman, M. D. Thornquist et al., "Risk factors for lung cancer and for intervention effects in CARET, the beta-carotene and retinol efficacy trial," Journal of the National Cancer Institute, vol. 88, no. 21, pp. 1550-1559, 1996.
[13] D. Albanes, O. P. Heinonen, J. K. Huttunen et al., "Effects of $\alpha$ tocopherol and $\beta$-carotene supplements on cancer incidence in the Alpha-Tocopherol Beta-Carotene Cancer Prevention Study," American Journal of Clinical Nutrition, vol. 62, no. 6, 1995.

[14] N. van Zandwijk, O. Dalesio, U. Pastorino, N. de Vries, and H. van Tinteren, "EUROSCAN, a randomized trial of vitamin $\mathrm{A}$ and $\mathrm{N}$-acetylcysteine in patients with head and neck cancer or lung cancer. For the EUropean Organization for Research and Treatment of Cancer Head and Neck and Lung Cancer Cooperative Groups," Journal of the National Cancer Institute, vol. 92, no. 12, pp. 977-986, 2000.

[15] T. Byers, "What can randomized controlled trial tell us about nutrition and cancer prevention?" Ca-A Cancer Journal for Clinicians, vol. 49, no. 6, pp. 353-361, 1999.

[16] F. R. Datema, M. B. Ferrier, and R. J. Baatenburg de Jong, "Impact of severe malnutrition on short-term mortality and overall survival in head and neck cancer," Oral Oncology, 2011.

[17] S. A. Duffy, D. L. Ronis, S. McLean et al., "Pretreatment health behaviors predict survival among patients with head and neck squamous cell carcinoma," Journal of Clinical Oncology, vol. 27, no. 12, pp. 1969-1975, 2009.

[18] A. Rodgman and T. A. Perfetti, "The chemical components identified in tobacco and tobacco smoke prior to 1954: a chronology of classical chemistry," Beitrage zur Tabakforschung International, vol. 23, no. 5, pp. 277-333, 2009.

[19] D. F. Church and W. A. Pryor, "Free-radical chemistry of cigarette smoke and its toxicological implications," Environmental Health Perspectives, vol. 64, pp. 111-126, 1985.

[20] B. Halliwell, "Oxidative stress and cancer: have we moved forward?” Biochemical Journal, vol. 401, no. 1, pp. 1-11, 2007.

[21] M. Panayiotidis, "Reactive oxygen species (ROS) in multistage carcinogenesis," Cancer Letters, vol. 266, no. 1, pp. 3-5, 2008.

[22] W. M. Baird, L. A. Hooven, and B. Mahadevan, "Carcinogenic polycyclic aromatic hydrocarbon-DNA adducts and mechanism of action," Environmental and Molecular Mutagenesis, vol. 45, no. 2-3, pp. 106-114, 2005.

[23] B. van Loon, E. Markkanen, and U. Hübscher, "Oxygen as a friend and enemy: how to combat the mutational potential of 8-oxo-guanine," DNA Repair, vol. 9, no. 6, pp. 604-616, 2010.

[24] B. Halliwell, "The antioxidant paradox," The Lancet, vol. 355, no. 9210, pp. 1179-1180, 2000.

[25] U. Harréus, P. Baumeister, S. Zieger, and C. Matthias, "The influence of high doses of vitamin $\mathrm{C}$ and zinc on oxidative DNA damage," Anticancer Research, vol. 25, no. 5, pp. 31973201, 2005.

[26] S. Renaud, M. De Lorgeril, R. Rylander, B. Hennig, and D. Heimburger, "The French paradox: dietary factors and cigarette smoking-related health risks," Annals of the New York Academy of Sciences, vol. 686, pp. 299-309, 1993.

[27] J. B. German and R. L. Walzem, "The health benefits of wine," Annual Review of Nutrition, vol. 20, pp. 561-593, 2000.

[28] L. L. Greasy and M. Coffee, "Phytoalexin production potential of grape berries," Journal of the American Society for Horticultural Science, vol. 113, pp. 230-234, 1998.

[29] T. M. A. El Attar and A. S. Virji, "Modulating effect of resveratrol and quercetin on oral cancer cell growth and proliferation," Anti-Cancer Drugs, vol. 10, no. 2, pp. 187-193, 1999.

[30] M. Athar, J. H. Back, X. Tang et al., "Resveratrol: a review of preclinical studies for human cancer prevention," Toxicology and Applied Pharmacology, vol. 224, no. 3, pp. 274-283, 2007.

[31] A. Bishayee, "Cancer prevention and treatment with resveratrol: from rodent studies to clinical trials," Cancer Prevention Research, vol. 2, no. 5, pp. 409-418, 2009. 
[32] M. A. Rahman, A. R. M. R. Amin, and D. M. Shin, "Chemopreventive potential of natural compounds in head and neck cancer," Nutrition and Cancer, vol. 62, no. 7, pp. 973-987, 2010.

[33] C. Nepka, E. Asprodini, and D. Kouretas, “Tannins, xenobiotic metabolism and cancer chemoprevention in experimental animals," European Journal of Drug Metabolism and Pharmacokinetics, vol. 24, no. 2, pp. 183-189, 1999.

[34] M. Nomura, H. Tsukada, D. Ichimatsu, H. Ito, T. Yoshida, and K. I. Miyamoto, "Inhibition of epidermal growth factorinduced cell transformation by tannins," Phytochemistry, vol. 66, no. 17, pp. 2038-2046, 2005.

[35] T. Walle, A. M. Browning, L. L. Steed, S. G. Reed, and U. K. Walle, "Flavonoid glucosides are hydrolyzed and thus activated in the oral cavity in humans," Journal of Nutrition, vol. 135, no. 1, pp. 48-52, 2005.

[36] K. Murota and J. Terao, "Antioxidative flavonoid quercetin: implication of its intestinal absorption and metabolism," Archives of Biochemistry and Biophysics, vol. 417, no. 1, pp. 1217, 2003.

[37] K. Min and S. E. Ebeler, "Quercetin inhibits hydrogen peroxide-induced DNA damage and enhances DNA repair in Caco-2 cells," Food and Chemical Toxicology, vol. 47, no. 11, pp. 2716-2722, 2009.

[38] D. Metodiewa, A. K. Jaiswal, N. Cenas, E. Dickancaité, and J. Segura-Aguilar, "Quercetin may act as a cytotoxic prooxidant after its metabolic activation to semiquinone and quinoidal product," Free Radical Biology and Medicine, vol. 26, no. 1-2, pp. 107-116, 1999.

[39] S. De, R. N. Chakraborty, S. Ghosh, A. Sengupta, and S. Das, "Comparative evaluation of cancer chemopreventive efficacy of alpha-tocopherol and quercetin in a murine model," Journal of Experimental and Clinical Cancer Research, vol. 23, no. 2, pp. 251-258, 2004.

[40] H. H. S. Chow and I. A. Hakim, "Pharmacokinetic and chemoprevention studies on tea in humans," Pharmacological Research, vol. 64, no. 2, pp. 105-112, 2011.

[41] C. S. Yang, P. Maliakal, and X. Meng, "Inhibition of carcinogenesis by tea," Annual Review of Pharmacology and Toxicology, vol. 42, pp. 25-54, 2002.

[42] S. Ermakova, B. Y. Choi, H. S. Choi, B. S. Kang, A. M. Bode, and Z. Dong, "The intermediate filament protein vimentin is a new target for epigallocatechin gallate," Journal of Biological Chemistry, vol. 280, no. 17, pp. 16882-16890, 2005.

[43] M. Li, Z. He, S. Ermakova et al., "Direct inhibition of insulin-like growth factor-I receptor kinase activity by (-)epigallocatechin-3-gallate regulates cell transformation," Cancer Epidemiology Biomarkers and Prevention, vol. 16, no. 3, pp. 598-605, 2007.

[44] J. H. Shim, Z. Y. Su, J. I. Chae et al., "Epigallocatechin gallate suppresses lung cancer cell growth through Ras-GTPaseactivating protein $\mathrm{SH} 3$ domain-binding protein 1," Cancer Prevention Research, vol. 3, no. 5, pp. 670-679, 2010.

[45] Z. Hou, S. Sang, H. You et al., "Mechanism of action of (-)-epigallocatechin-3-gallate: auto-oxidation- dependent inactivation of epidermal growth factor receptor and direct effects on growth inhibition in human esophageal cancer KYSE 150 cells," Cancer Research, vol. 65, no. 17, pp. 80498056, 2005.

[46] Y. C. Liang, S. Y. Lin-shiau, C. F. Chen, and J. K. Lin, "Suppression of extracellular signals and cell proliferation through EGF receptor binding by (-)-epigallocatechin gallate in human A431 epidermoid carcinoma cells," Journal of Cellular Biochemistry, vol. 67, no. 1, pp. 55-65, 1997.
[47] M. Shimizu, A. Deguchi, J. T. E. Lim, H. Moriwaki, L. Kopelovich, and I. B. Weinstein, "(-)-Epigallocatechin gallate and polyphenon $\mathrm{E}$ inhibit growth and activation of the epidermal growth factor receptor and human epidermal growth factor receptor-2 signaling pathways in human colon cancer cells," Clinical Cancer Research, vol. 11, no. 7, pp. 27352746, 2005.

[48] S. Adachi, T. Nagao, H. I. Ingolfsson et al., "The inhibitory effect of (-)-epigallocatechin gallate on activation of the epidermal growth factor receptor is associated with altered lipid order in HT29 colon cancer cells," Cancer Research, vol. 67, no. 13, pp. 6493-6501, 2007.

[49] C. S. Yang, H. Wang, G. X. Li, Z. Yang, F. Guan, and H. Jin, "Cancer prevention by tea: evidence from laboratory studies," Pharmacological Research, vol. 64, no. 2, pp. 113-122, 2011.

[50] K. Boehm, F. Borrelli, E. Ernst et al., "Green tea (Camellia sinensis) for the prevention of cancer," Cochrane Database of Systematic Reviews, no. 3, Article ID CD005004, 2009.

[51] A. Khafif, S. P. Schantz, T. C. Chou, D. Edelstein, and P. G. Sacks, "Quantitation of chemopreventive synergism between (-)-epigallocatechin-3-gallate and curcumin in normal, premalignant and malignant human oral epithelial cells," Carcinogenesis, vol. 19, no. 3, pp. 419-424, 1998.

[52] N. Li, X. Chen, J. Liao et al., "Inhibition of 7,12dimethylbenz[a]anthracene (DMBA)-induced oral carcinogenesis in hamsters by tea and curcumin," Carcinogenesis, vol. 23, no. 8, pp. 1307-1313, 2002.

[53] A. L. Chen, C. H. Hsu, J. K. Lin et al., "Phase I clinical trial of curcumin, a chemopreventive agent, in patients with high-risk or pre-malignant lesions," Anticancer Research, vol. 21, no. 4, pp. 2895-2900, 2001.

[54] B. Rai, J. Kaur, R. Jacobs, and J. Singh, "Possible action mechanism for curcumin in pre-cancerous lesions based on serum and salivary markers of oxidative stress," Journal of Oral Science, vol. 52, no. 2, pp. 251-256, 2010.

[55] C. L. Kuo, S. Y. Wu, S. W. Ip et al., "Apoptotic death in curcumin-treated NPC-TW 076 human nasopharyngeal carcinoma cells is mediated through the ROS, mitochondrial depolarization and caspase-3-dependent signaling responses," International Journal of Oncology, vol. 39, no. 2, pp. 319-328, 2011.

[56] S. Liao, J. Xia, Z. Chen et al., "Inhibitory effect of curcumin on oral carcinoma CAL-27 cells via suppression of notch-1 and NF- $\kappa$ B signaling pathways," Journal of Cellular Biochemistry, vol. 112, no. 4, pp. 1055-1065, 2011.

[57] Y. T. Lin, L. F. Wang, and Y. C. Hsu, "Curcuminoids suppress the growth of pharynx and nasopharyngeal carcinoma cells through induced apoptosis," Journal of Agricultural and Food Chemistry, vol. 57, no. 9, pp. 3765-3770, 2009.

[58] C. Sharma, J. Kaur, S. Shishodia, B. B. Aggarwal, and R. Ralhan, "Curcumin down regulates smokeless tobaccoinduced NF- $\kappa$ B activation and COX-2 expression in human oral premalignant and cancer cells," Toxicology, vol. 228, no. 1, pp. 1-15, 2006.

[59] M. M. Lotempio, M. S. Veena, H. L. Steele et al., "Curcumin suppresses growth of head and neck squamous cell carcinoma," Clinical Cancer Research, vol. 11, no. 19, pp. 69947002, 2005.

[60] C. R. Leemans, B. J. M. Braakhuis, and R. H. Brakenhoff, "The molecular biology of head and neck cancer," Nature Reviews Cancer, vol. 11, no. 1, pp. 9-22, 2011.

[61] P. Baumeister, S. Schwenk-Zieger, M. Reiter, C. Welz, and U. Harréus, "Transforming Growth Factor-alpha reduces carcinogen-induced DNA damage in mini-organ cultures 
from head-and-neck cancer patients," Mutation Research, vol. 677, no. 1-2, pp. 42-45, 2009.

[62] P. Baumeister, K. Heinrich, M. Märte, M. Reiter, S. SchwenkZieger, and U. Harréus, "The impact of EGFR stimulation and inhibition on BPDE induced DNA fragmentation in oral/oropharyngeal mucosa in vitro," Oral Oncology, vol. 47, pp. 1141-1147, 2011.

[63] J. M. Yang, G. F. Sullivan, and W. N. Hiat, "Regulation of the function of P-glycoprotein by epidermal growth factor through phospholipase C," Biochemical Pharmacology, vol. 53, no. 11, pp. 1597-1604, 1997.

[64] P. Myllynen, T. Kurttila, L. Vaskivuo, and K. Vähäkangas, "DNA damage caused by benzo(a)pyrene in MCF-7 cells is increased by verapamil, probenecid and PSC833," Toxicology Letters, vol. 169, no. 1, pp. 3-12, 2007.

[65] G. C. Yeh, J. Lopaczynska, C. M. Poore, and J. M. Phang, "A new functional role for P-glycoprotein: efflux pump for benzo(a)pyrene in human breast cancer MCF-7 cells," Cancer Research, vol. 52, no. 23, pp. 6692-6695, 1992.

[66] K. K. Ang, B. A. Berkey, X. Tu et al., "Impact of epidermal growth factor receptor expression on survival and pattern of relapse in patients with advanced head and neck carcinoma," Cancer Research, vol. 62, no. 24, pp. 7350-7356, 2002.

[67] J. Baselga, J. M. Trigo, J. Bourhis et al., "Phase II multicenter study of the antiepidermal growth factor receptor monoclonal antibody cetuximab in combination with platinum-based chemotherapy in patients with platinum-refractory metastatic and/or recurrent squamous cell carcinoma of the head and neck," Journal of Clinical Oncology, vol. 23, no. 24, pp. 55685577, 2005.

[68] I. Martínez-Lacaci, P. Garcĺa Morales, J. L. Soto, and M. Saceda, "Tumour cells resistance in cancer therapy," Clinical and Translational Oncology, vol. 9, no. 1, pp. 13-20, 2007.

[69] B. Sarkadi, L. Homolya, G. Szakács, and A. Váradi, "Human multidrug resistance $\mathrm{ABCB}$ and ABCG transporters: participation in a chemoimmunity defense system," Physiological Reviews, vol. 86, no. 4, pp. 1179-1236, 2006.

[70] S. K. Steinsvåg, M. Strand, O. Berg, M. Miaguchi, and J. Olofsson, "Human respiratory mucosa in a nonadhesive stationary organ culture system," Laryngoscope, vol. 101, no. 12, pp. 1323-1331, 1991.

[71] N. H. Kleinsasser, J. Juchhoff, B. C. Wallner et al., "The use of mini-organ cultures of human upper aerodigestive tract epithelia in ecogenotoxicology," Mutation Research, vol. 561, no. 1-2, pp. 63-73, 2004.

[72] IARC Monographs on the Evaluation of Carcinogenic Risks to Humans, "Tobacco smoke and involuntary smoking," IARC Working Group on the Evaluation of Carcinogenic Risks to Humans, vol. 83, pp. 1-1413, 2004.

[73] IARC Working Group on the Evaluation of Carcinogenic Risks to Humans, "Some non-heterocyclic polycyclic aromatic hydrocarbons and some related exposures," IARC Working Group on the Evaluation of Carcinogenic Risks to Humans, vol. 92, pp. 1-853, 2010.

[74] D. Warshawsky and J. R. Landolph, Molecular Carcinogenesis and the Molecular Biology of Human Cancer, CRC Press, New York, NY, USA, 2006.

[75] R. F. Newbold and P. Brookes, "Exceptional mutagenicity of a benzo[a]pyrene diol epoxide in cultured mammalian cells," Nature, vol. 261, no. 5555, pp. 52-54, 1976.

[76] M. F. Denissenko, A. Pao, M. S. Tang, and G. P. Pfeifer, "Preferential formation of benzo[a]pyrene adducts at lung cancer mutational hotspots in P53," Science, vol. 274, no. 5286, pp. 430-432, 1996.
[77] J. A. Imlay, S. M. Chin, and S. Linn, "Toxic DNA damage by hydrogen peroxide through the fenton reaction in vivo and in vitro," Science, vol. 240, no. 4852, pp. 640-642, 1988.

[78] IARC Monographs on the Evaluation of Carcinogenic Risks to Humans, Re-Evaluation of Some Organic Chemicals, Hydrazine and Hydrogen Peroxide, vol. 71, International Agency for Research on Cancer, Lyon, France, 1999.

[79] G. Speit, S. Hanelt, R. Helbig, A. Seidel, and A. Hartmann, "Detection of DNA effects in human cells with the comet assay and their relevance for mutagenesis," Toxicology Letters, vol. 88, no. 1-3, pp. 91-98, 1996.

[80] P. Baumeister, M. Reiter, N. Kleinsasser, C. Matthias, and U. Harréus, "Epigallocatechin-3-gallate reduces DNA damage induced by benzo[a]pyrene diol epoxide and cigarette smoke condensate in human mucosa tissue cultures," European Journal of Cancer Prevention, vol. 18, no. 3, pp. 230-235, 2009.

[81] P. Baumeister, M. Reiter, S. Zieger, C. Matthias, and U. Harréus, "DNA-protective potential of polyphenols in human mucosa cell cultures," HNO, vol. 56, no. 8, pp. 795-798, 2008.

[82] M. Reiter, K. Rupp, P. Baumeister, S. Zieger, and U. Harréus, "Antioxidant effects of quercetin and coenzyme Q10 in mini organ cultures of human nasal mucosa cells," Anticancer Research, vol. 29, no. 1, pp. 33-39, 2009.

[83] P. Møller, "The alkaline comet assay: towards validation in biomonitoring of DNA damaging exposures," Basic and Clinical Pharmacology and Toxicology, vol. 98, no. 4, pp. 336345, 2006.

[84] A. R. Collins, A. A. Oscoz, G. Brunborg et al., "The comet assay: topical issues," Mutagenesis, vol. 23, no. 3, pp. 143-151, 2008.

[85] P. L. Olive and J. P. Banáth, "The comet assay: a method to measure DNA damage in individual cells," Nature Protocols, vol. 1, no. 1, pp. 23-29, 2006.

[86] S. Devaraj and I. Jialal, "Failure of vitamin E in clinical trials: is gamma-tocopherol the answer?" Nutrition Reviews, vol. 63, no. 8, pp. 290-293, 2005.

[87] Q. Jiang, S. Christen, M. K. Shigenaga, and B. N. Ames, " $\gamma$-Tocopherol, the major form of vitamin $\mathrm{E}$ in the US diet, deserves more attention," American Journal of Clinical Nutrition, vol. 74, no. 6, pp. 714-722, 2001.

[88] H. Y. Huang and L. J. Appel, "Supplementation of diets with $\alpha$-tocopherol reduces serum concentrations of $\gamma$ - and $\delta$ tocopherol in humans," Journal of Nutrition, vol. 133, no. 10, pp. 3137-3140, 2003. 


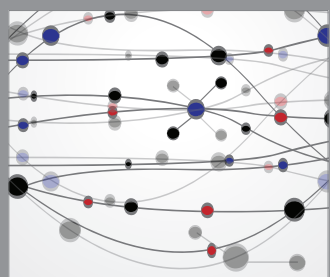

The Scientific World Journal
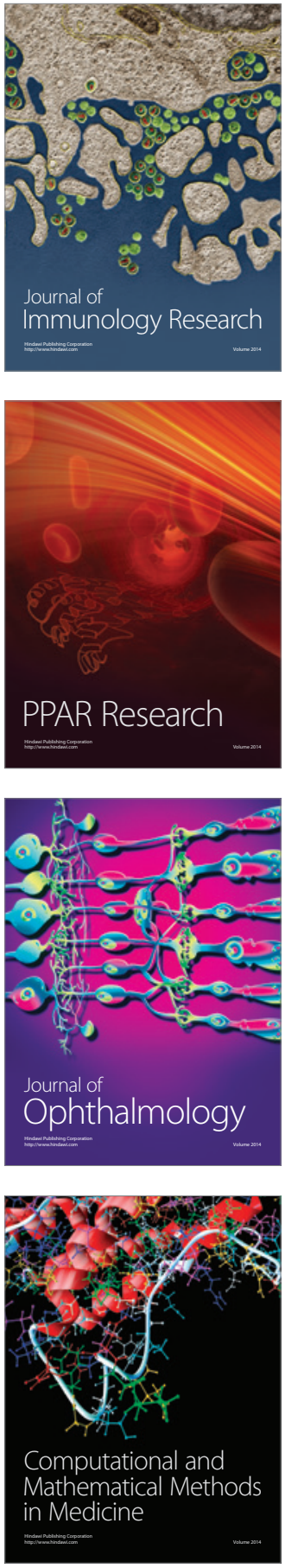

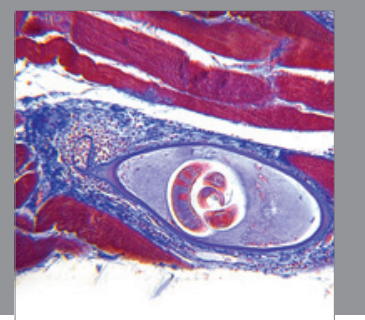

Gastroenterology

Research and Practice
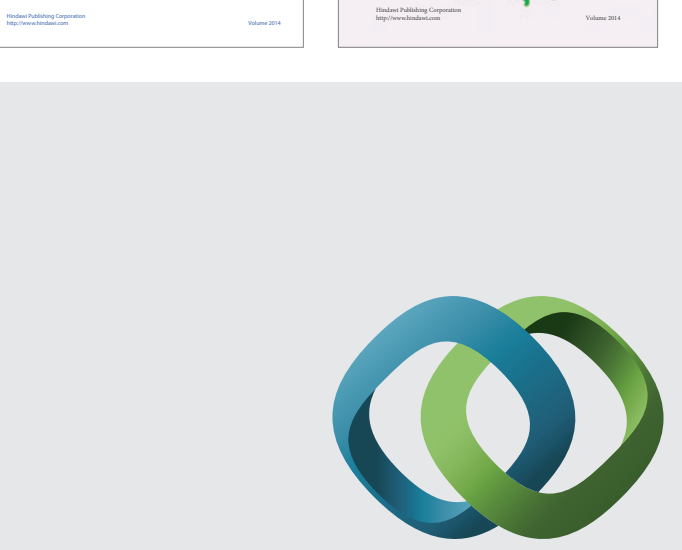

\section{Hindawi}

Submit your manuscripts at

http://www.hindawi.com
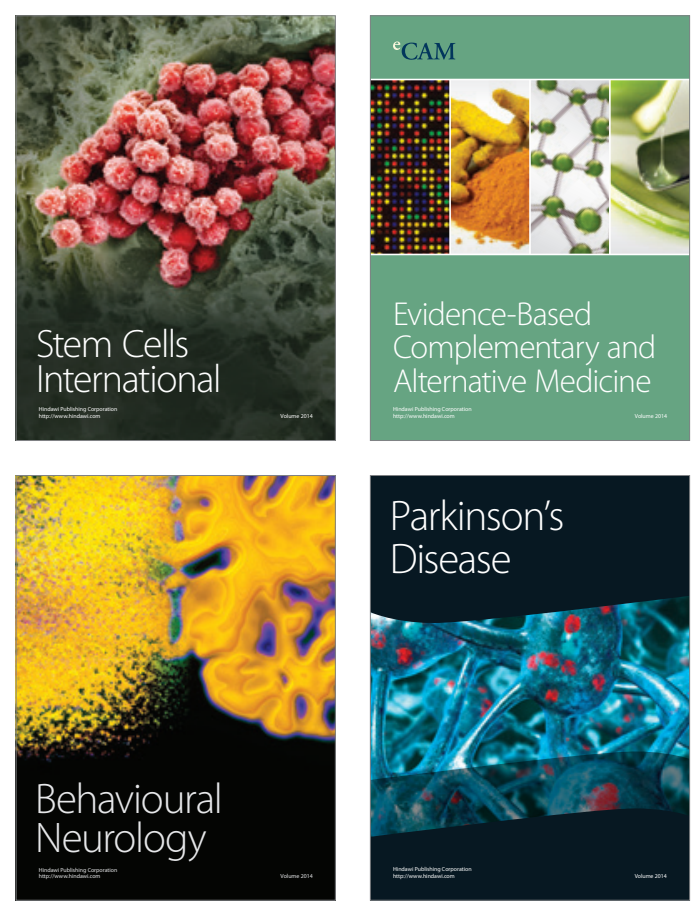

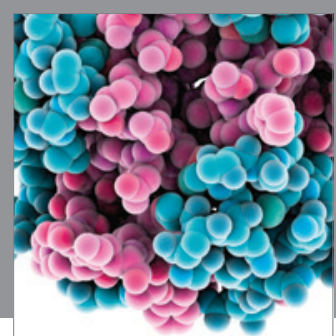

Journal of
Diabetes Research

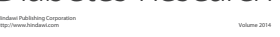

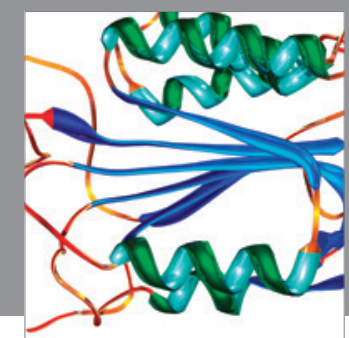

Disease Markers
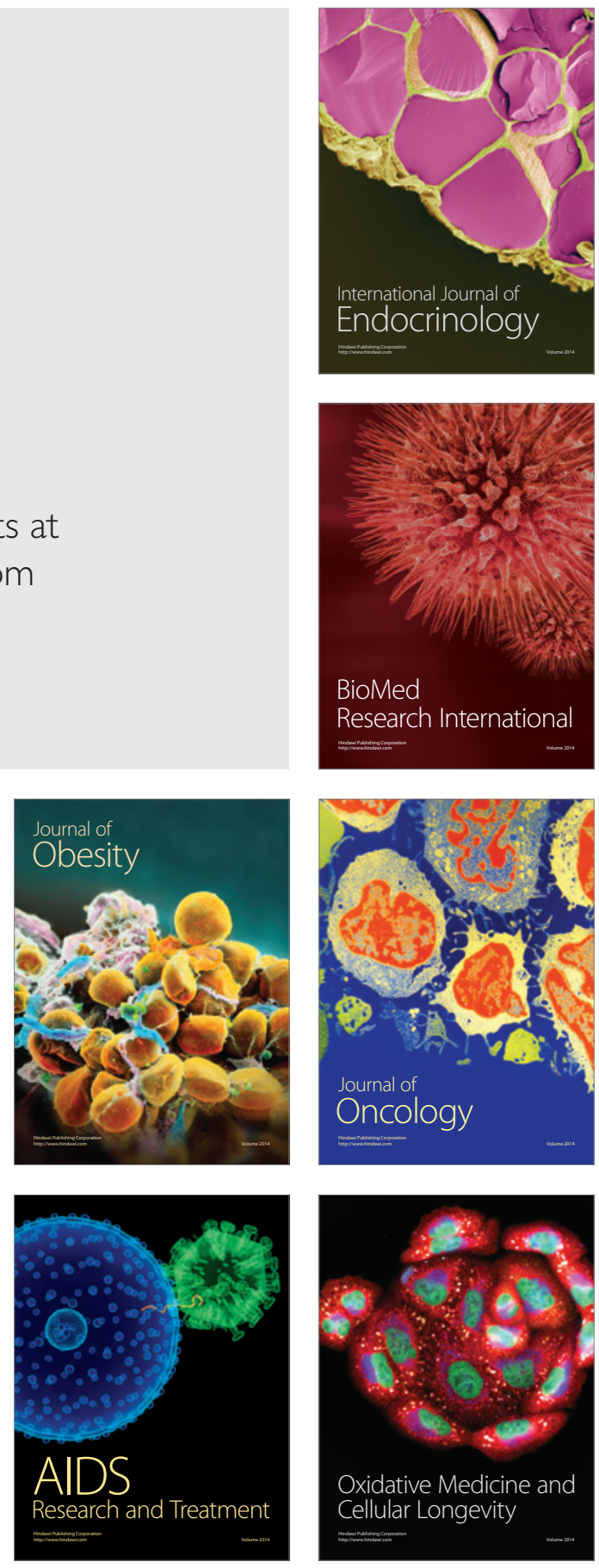